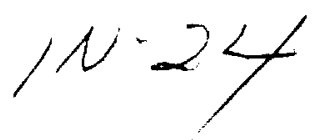

NASA Technical Memorandum 106121

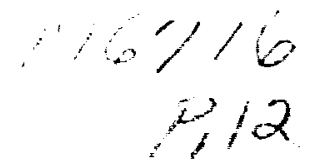

\title{
Assessment of Damage in Ceramics and Ceramic Matrix Composites Using Ultrasonic Techniques
}

Y.C. Chu

The Ohio State University

Columbus, Ohio

G.Y. Baaklini

Lewis Research Center

Cleveland, Ohio

and

S.I. Rokhlin

The Ohio State University

Columbus, Ohio

May 1993

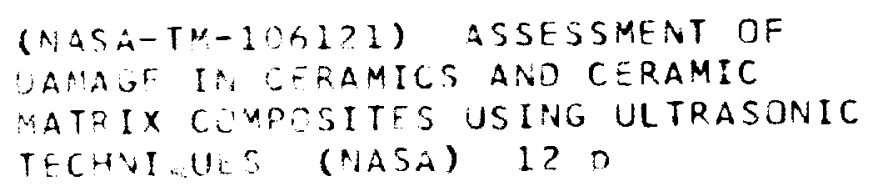

$63 / 24 \quad 0176716$ 
. 


\title{
ASSESSMENT OF DAMAGE IN CERAMICS AND CERAMIC MATRIX COMPOSITES
}

\section{USING ULTRASONIC TECHNIQUES}

\author{
Y.C. Chu and S.I. Rokhlin \\ Ohio State University \\ Department of Welding Engineering \\ Columbus, Ohio $\mathbf{4 3 2 1 0}$ \\ and \\ G.Y. Baaklini \\ National Aeronautics and Space Administration \\ Lewis Research Center \\ Cleveland, Ohio 44135
}

\section{SUMMARY}

This paper addresses the application of ultrasonic sensing to damage assessment in ceramics and ceramic matrix composites. It focuses on damage caused by thermal shock or oxidation at elevated temperatures, which often results in elastic anisotropy. This damaged-induced anisotropy is determined by measuring the velocities of ultrasonic waves in different propagation directions. Thermal shock damage is assessed in ceramic samples of reaction bonded silicon nitride (RBSN). Thermal shock treatment from different temperatures up to $1000^{\circ} \mathrm{C}$ is applied to produce the microcracks. Results indicate that most microcracks produced by thermal shock are located near sample surfaces. Ultrasonic measurements using the surface wave method are found to correlate well with measurements of degradation of mechanical properties obtained independently by other authors using destructive methods. Oxidation damage is assessed in silicon carbide fiber/reaction bonded silicon nitride matrix (SCS-6/RBSN) composites. The oxidation is done by exposing the samples in a flowing oxygen environment at elevated temperatures, up to $1400^{\circ} \mathrm{C}$, for $100 \mathrm{hr}$. The Young's modulus in the fiber direction as obtained from ultrasonic measurements decreases significantly at $600^{\circ} \mathrm{C}$ but retains its original value at temperatures above $1200^{\circ} \mathrm{C}$. This agrees well with the results of destructive tests by other authors. On the other hand, the transverse moduli obtained from ultrasonic measurements decrease continually until $1200^{\circ} \mathrm{C}$. Measurements on the shear stiffnesses show behavior similar to the transverse moduli. The results of this work show that the damage-induced anisotropy in both ceramics and ceramic matrix composites can be determined successfully by ultrasonic methods. This suggests the possibility of assessing damage severity using ultrasonic techniques.

\section{INTRODUCTION}

The inherent brittleness of ceramic materials often results in catastrophic failure due to microcrack damage caused by thermal treatment or mechanical loading. Usually the microcracks arise from grain anisotropy and will be of approximately grain size. Once the grain size in ceramics exceeds the critical limit, microcracks form spontaneously, thus resulting in an increase in microcrack density. As a result, permanent degradation in stiffness and strength and change in elastic anisotropy will occur in microcracked ceramics. A schematic four-stage pattern has been established for temperature dependence of strength degradation in alumina due to thermal shock (refs. 1 and 2).

The fracture resistance of the ceramic materials can be improved by reinforcing them with continuous fibers. However, in a high temperature environment the fiber-matrix interfaces in ceramic matrix 
composites often suffer from oxidation reactions caused by diffusion of oxygen through the matrix. It is known that the properties of ceramic materials reinforced by continuous fibers are dominated by the interface. Thus, ceramic matrix composites subjected to thermal oxidation treatments may not retain the desired strength and toughness (ref. 3).

In this study we applied ultrasonic techniques to assess the damage in ceramics due to thermal shock and the damage in ceramic matrix composites due to thermal oxidation. By measuring the damageinduced elastic anisotropy, we aimed to correlate ultrasonic measurements with the degradation in mechanical properties of ceramics and ceramic matrix composites.

\section{EXPERIMENTAL APPROACH}

All the SiC/RBSN composite and RBSN ceramic samples used in this study were obtained from NASA Lewis Research Center. One unidirectional $[0]_{28} \mathrm{SiC} / \mathrm{RBSN}$ composite sample (745) and a monolithic RBSN sample (723) were used in this study. The composite sample has 30 percent fiber fraction and 30 percent matrix porosity. The monolithic RBSN sample has 22 percent porosity. Both as-received and oxidized samples have smooth surfaces; thus further surface finishing is not required.

For ultrasonic assessment of thermal shock damage, RBSN ceramic samples were first given thermal shock from a predetermined temperature and then evaluated by both bulk and surface wave methods. Thermal shock is applied to the samples by first slowly heating them to elevated temperature, then holding at stabilized temperature for at least $15 \mathrm{~min}$, followed by quenching into ice water.

For ultrasonic assessment of thermal oxidation damage, the composite sample $\mathbf{7 4 5}$ was cut into three pieces for thermal oxidation experiments after the initial ultrasonic evaluation had been done. The thermal oxidation treatment is applied to the samples by directly heating the samples in flowing oxygen for $100 \mathrm{hr}$ at different temperatures. The effect of damage due to thermal oxidation was evaluated using the bulk wave method after the samples had been heat treated in an oxygen environment at elevated temperatures and by comparison with ultrasonic results obtained prior to oxidation.

In this study, different ultrasonic techniques (refs. 4 and 5) for the measurement of bulk and surface properties are used. For the bulk properties, a self-referenced bulk wave method (ref. 4) is used. The basic idea of this method is illustrated schematically in figure 1 . In this method the phase velocity at normal incidence is measured with high precision by overlapping multiple reflected signals from the front and back surfaces of the sample. Phase velocities at oblique incidence are calculated using the phase velocity in the normal direction and the time delay change for the rotated sample (due to the acoustic path length change in the sample relative to that at normal incidence):

$$
\mathrm{V}_{\theta}=\left[\frac{1}{\mathrm{~V}_{\mathrm{n}}^{2}}+\frac{\Delta \mathrm{t}_{0}-\left(\Delta \mathrm{t}_{\mathrm{o}}+\Delta \mathrm{t}_{\theta}\right) \cos \theta}{\mathrm{hV}_{\mathrm{o}}}+\frac{\Delta \mathrm{t}_{\theta}\left(2 \Delta \mathrm{t}_{\mathrm{o}}+\Delta \mathrm{t}_{\theta}\right)}{4 \mathrm{~h}^{2}}\right]^{-1 / 2}
$$

Here $V_{n}$ is the phase velocity at normal incidence, $V_{0}$ is the sound speed in water, $h$ is the thickness of the sample, $\Delta t_{0}=2 h\left(1 / V_{0}-1 / V_{n}\right)$, and $\Delta t_{\theta}$ is the difference in the time-of-flight measurements between normal incidence and arbitrary oblique incidence at incident angle $\theta$. Short pulses ( 1 to 1.5 periods) with central frequencies 2.25 or $5 \mathrm{MHz}$ were used in the self-referenced measurements. 
According to Hasselman (ref. 1) numerous microcracks will initiate from sample surfaces as the thermal shock treatment is applied to alumina. Thus an effective technique for assessment of thermal shock damage should be sensitive to the property change in the near-surface region. For this reason, a surface wave method (ref. 5) measuring the Rayleigh wave velocity is used. The velocity of the Rayleigh wave is very useful for characterizing the change of near-surface properties due to surface wave energy localization. Using Snell's law, the Rayleigh wave velocity can be determined by

$$
\mathrm{V}_{\mathrm{R}}=\frac{\mathrm{V}_{\mathrm{o}}}{\sin \theta_{\mathrm{R}}}
$$

where $V_{R}$ is the Rayleigh wave velocity and $\theta_{R}$ is the Rayleigh critical angle. Here $\theta_{R}$ can be measured precisely by finding the incident angle corresponding to the dip in the reflection coefficient curve.

Ultrasonic measurements were made in the computer-controlled goniometer shown in figure 2. Angle resolution and repeatability were better than $0.01 \mathrm{deg}$. The water temperature inside the goniometer was stabilized at $29.8 \pm 0.2^{\circ} \mathrm{C}$. The advantage of this experimental system is that both transmitted and reflected ultrasonic signals can be measured at oblique incidence using one transducer. The received signal is averaged and digitized by a LeCroy $9400125-\mathrm{MHz}$ digital oscilloscope. The time delay is measured as a function of incident angle and is used to calculate wave propagation velocities at different refraction angles.

\section{ULTRASONIC ASSESSMENT OF THERMAL SHOCK DAMAGE IN RBSN CERAMICS}

As a result of thermal shock, numerous microcracks are formed in ceramics resulting in permanent reduction of strength and elastic moduli. A schematic representation of strength as a function of thermal shock severity is shown in figure 3 .

Following Boley and Weiner (ref. 6) and Hasselman (ref. 2), it can be shown that tensile strength after thermal shock $\mathrm{S}_{\mathrm{a}}$ can be estimated by

$$
S_{a}=\left(\frac{8 G_{1} G_{2}^{2} E^{3} N_{S}}{S_{t}^{2} b}\right)^{1 / 4}
$$

where $E$ is the Young's modulus of the ceramic after thermal shock, $S_{t}$ is the original strength of the material, $G_{1}$ is the fracture energy per unit area in the thermal shock experiment, $G_{2}$ is the surface fracture energy in a strength test experiment, $N_{S}$ is the crack density per unit area, and $b$ is the rod diameter. It has been suggested by several investigators (ref. 7) that $G_{1}=G_{2}=G$ where $G$ is the surface fracture energy of the undamaged material. Note that equation (3) predicts that the post thermal shock strength is proportional to $E^{3 / 4}$ and $1 / \sqrt{S_{t}}$. Since the change in elastic properties can be evaluated by ultrasonic techniques, this equation thus serves as the basis for ultrasonic assessment of damage and strength prediction by measuring the elastic properties of damaged material.

Monolithic RBSN samples after thermal shock from different elevated temperatures were investigated by both bulk wave and surface wave methods. Figure 4 shows the changes of Rayleigh critical angle due to thermal shock from different temperatures. The measurements were obtained using short pulses with a 
central frequency of $2.25 \mathrm{MHz}$. Note that the change in Rayleigh critical angle due to thermal shock from temperatures above $400^{\circ} \mathrm{C}$ is more than $1^{\circ}$ (5 percent), which indicates that the surface wave method is relatively sensitive to damage due to thermal shock. Figure 5 shows results of bulk wave measurements for longitudinal waves. It is found that monolithic RBSN ceramics become anisotropic after thermal shock from temperature higher than $425^{\circ} \mathrm{C}$. However, the changes in bulk wave measurements due to thermal shock from $800^{\circ} \mathrm{C}$ are found to be less than 3 percent. From the results of both methods, we conclude that the effect of damage due to thermal shock from temperatures below $800{ }^{\circ} \mathrm{C}$ is mainly on surface properties rather than bulk properties. In other words, most of the damage resulting from thermal shock is located near the surface. This also explains why four-point bending tests are more sensitive to damage due to thermal shock than are tensile tests (ref. 8). Moreover, the reduction of Rayleigh wave velocities due to thermal shock is very similar to the reduction of ultimate bending strength. Figure 6 shows the reduction of Rayleigh wave velocities and ultimate bending strength in the same graph. It is clear that the ultrasonically-measured data is well correlated with the results of four-point bending tests. This means that the surface wave method might be useful for examining the effect of damage on the ultimate strength of ceramic materials and for determination of the critical temperature for thermal shock. It is also important that the critical temperature corresponding to damage initiation can be determined with confidence by the ultrasonic method.

\section{ULTRASONIC ASSESSMENT OF THERMAL OXIDATION DAMAGE}

$\mathrm{SiC} / \mathrm{RBSN}$ composite are composed of CVD SiC fibers (SCS-6 from Textron), porous $\mathrm{RBSN}\left(\mathrm{Si}_{3} \mathrm{~N}_{4}\right)$ matrix and a carbon-rich coating as the interface between fiber and matrix. The CVD SiC fiber has a complex microstructure with a graphite-coated carbon core in the center surrounded by a transition zone and then a layer of $\beta$-Sic. The carbon-rich coating on the fiber surface is basically a mixture of graphite carbon and fine $\mathrm{SiC}$ particles. The RBSN matrix $\left(\mathrm{Si}_{3} \mathrm{~N}_{4}\right)$ has 20 to 40 percent porosity and a small amount of unreacted silicon. Most pores in the matrix are interconnected, which allows the oxygen to reach the fiber-matrix interface. From the components of SiC/RBSN composites and their microstructure, several oxidation reactions in an oxidizing environment at high temperature can be expected (ref. 3 ):

$$
\begin{gathered}
2 \mathrm{SiC}+3 \mathrm{O}_{2} \rightarrow 2 \mathrm{SiO}_{2}+2 \mathrm{CO} \\
\mathrm{Si}_{3} \mathrm{~N}_{4}+3 \mathrm{O}_{2} \rightarrow 3 \mathrm{SiO}_{2}+2 \mathrm{~N}_{2} \\
2 \mathrm{C}+\mathrm{O}_{2} \rightarrow 2 \mathrm{CO} \\
\mathrm{C}+\mathrm{O}_{2} \rightarrow \mathrm{CO}_{2} \\
\mathrm{Si}+\mathrm{O}_{2} \rightarrow \mathrm{SiO}_{2}
\end{gathered}
$$

The oxidation reactions (eqs. (5) and (8)) might affect the properties of the RBSN matrix. The oxidation reactions (eqs. (6) and (7)) may lead to degradation of the carbon core and the fiber-matrix interface. The oxidation reactions (eqs. (4) and (8)) might cause degradation of the SiC fiber. According to Bhatt (ref. 3) the strength and stiffness of $\mathrm{SiC} / \mathrm{RBSN}$ composites are severely reduced after oxidation at different temperatures. It is clear that the reduction in mechanical properties of the composites should be the 
results of the above oxidation effect. However, among different oxidation mechanisms which one is the dominant mechanism for the degradation in mechanical properties of the composites is still not very clear. Identifying the dominant oxidation mechanism for composite degradation is crucial for improving the high-temperature stability of ceramic matrix composites. Thus, one of the objectives of the present work is to investigate the dominant oxidation mechanism for the degradation in mechanical properties of ceramic matrix composites. Different oxidation mechanisms will result in different elastic anisotropy. By measuring the elastic anisotropy caused by oxidation at different temperatures, we can identify the dominant oxidation mechanism. This is done by analyzing the correlation between composite microstructures and ultrasonic measurements.

The composite sample (745) which had been evaluated prior to oxidation study was cut into three pieces $(745 a, 745 b$, and $745 c)$ for experiments on thermal oxidation at different temperatures. The temperatures for thermal oxidation of these samples were fixed at 600,1200 , and $1400^{\circ} \mathrm{C}$, respectively. The samples after heat treatment in flowing oxygen for $100 \mathrm{hr}$ were evaluated using the bulk ultrasonic wave method. A 2.25-MHz transducer was used for all the samples because of the high attenuation due to damage in SiC/RBSN composites caused by thermal oxidation.

As a result of oxidation damage, the elastic anisotropy of the composite samples changes, which results in different angular dependence of the ultrasonic phase velocities. Figure 7 shows the comparison between the ultrasonic measurements of phase velocities for both quasi-longitudinal and quasi-shear waves before and after oxidation at $1200^{\circ} \mathrm{C}$. As one can see significant change in phase velocities of both waves and their angular dependence is found due to oxidation damage. From the velocity data for samples oxidized at different temperatures, their elastic properties can be obtained using the nonlinear least-squares optimization procedure described in reference 4. Figure 8 shows an example of this optimization, where the measured data are shown as discrete points and the solid lines are theoretical values calculated from the reconstructed elastic constants. Results of this optimization are listed in table I. The material density before and after oxidation is also listed in table I. As one can see from the density data impregnation of pores by water during the immersion measurements is significantly reduced after oxidation at temperatures above $1200^{\circ} \mathrm{C}$. This reduction in water saturation density agrees consistently with Bhatt's study (ref. 3). According to Bhatt, a layer of oxide diffusion barrier was found on the surfaces of the samples, which minimizes the diffusion of oxygen through the pores. In our experiment, we found that this oxide layer actually blocks most of the matrix porosity (originally open and interconnected) from the surrounding environment.

With the results shown in table I, one can estimate the Young's modulus for samples oxidized at different temperatures. The effect of thermal oxidation on the Young's modulus in the fiber direction is shown in figure 9 where the circular points are results of tensile tests reported by Bhatt (ref. 3 ) and the rectangular points are results of ultrasonic measurements. As one can see, the agreement between these two results is good.

Two possible mechanisms for the reduction of mechanical properties are suggested in Bhatt's report (ref. 3). One is the oxidation of the fiber surface coating and the other is the oxidation of the carbon core. According to Bhatt, the oxidation of the carbon core at temperatures beyond $400{ }^{\circ} \mathrm{C}$ extends at least $20 \mathrm{~mm}$ from the sample ends. Oxidation of the fiber coating was found at 600 and $1000{ }^{\circ} \mathrm{C}$ in the cross section $25 \mathrm{~mm}$ from the sample ends. It is known that the effect of the fiber-matrix interface should be reflected mostly in the transverse and shear stiffnesses, but only slightly in the longitudinal stiffness. Thus the ultrasonic results suggest that the dominant mechanism for the reduction of the transverse moduli $\mathrm{C}_{22}$ and $\mathrm{C}_{33}$ listed in table I should be the oxidation of the fiber coating. 
The dominant mechanism for the reduction of the longitudinal stiffness (especially at $600{ }^{\circ} \mathrm{C}$ ) is still not very clear. However, from the micromechanical analysis of ceramic matrix composites (ref. 4), the reduction of the longitudinal stiffness should be mainly due to the degradation of the SiC fiber. Also it should be noted that the samples used for ultrasonic evaluation are shorter $\left(58 \mathrm{~mm}\right.$ for $600{ }^{\circ} \mathrm{C}, 30 \mathrm{~mm}$ for $1200^{\circ} \mathrm{C}$, and $28 \mathrm{~mm}$ for $1400^{\circ} \mathrm{C}$ ) than those used for tensile tests (127 mm each). Oxidation through the sample ends could be crucial for shorter samples.

\section{SUMMARY}

This study focuses on nondestructive assessment of thermally induced damage in ceramics and ceramic matrix composites. Both ultrasonic bulk wave and surface wave methods were used to assess thermal shock damage in ceramics and thermal oxidation damage in ceramic matrix composites. The foundation of ultrasonic damage assessment lies in the effect of damage on elastic properties. Ultrasonic measurements indicate that damage due to thermal shock is located near the surface; thus the surface wave has been found to be most appropriate for estimation of ultimate strength reduction and critical temperature for thermal shock. The angular dependence of both shear and longitudinal velocities has been found to be affected by thermal oxidation. The behavior of different elastic constants obtained by ultrasonic measurements suggests that the dominant mechanism for the reduction of the transverse and shear properties is oxidation of the fiber-matrix interface, while the reduction of the longitudinal stiffness could be due to degradation of $\mathrm{SiC}$ fibers. On the whole nondestructive evaluation of thermal oxidation effects and thermal shock shows good correlation with previously performed measurements by destructive methods.

\section{ACKNOWLEDGMENT}

This work was sponsored by NASA Lewis Research Center under grant NAG3-1220. The authors would like to thank Mr. Meir Hefetz for his help with experiments.

\section{REFERENCES}

1. Hasselman, D.P.H.: Unified Theory of Thermal Shock Fracture Initiation and Crack Propagation in Brittle Ceramics. J. Amer. Ceram. Soc., vol. 52, 1969, pp. 600-604.

2. Hasselman, D.P.H.: Strength Behavior of Polycrystalline Alumina Subjected to Thermal Shock. J. Amer. Ceram. Soc., vol. 53, 1970, pp. 490-495.

3. Bhatt, R.T.: Oxidation Effect on the Mechanical Properties of SiC Fiber-Reinforced Reaction-Bonded Silicon Nitride Matrix Composites. NASA TM-102360, 1989.

4. Chu, Y.C.; and Rokhlin, S.I.: Determination of Macro and Micromechanical and Interfacial Elastic Properties of Composites From Ultrasonic Data. J. Acoust. Soc. Am., vol. 92, 1992, pp. 920-931.

5. Hefetz, M.; and Rokhlin, S.I.: Thermal Impact Damage Assessment in Ceramics Using Ultrasonic Waves. Review of Progress in QNDE, D.O. Thompson and D.E. Chimenti, eds., Plenum Press, New York, 1992, p. 11.

6. Boley, B.A.; and Weiner, J.H.: Theory of Thermal Stresses. John Wiley \& Sons, Inc., New York, 1960. 
7. Davidge, R.W.; and Tappin, G.: Thermal Shock and Fracture in Ceramics. Trans. Brit. Ceram. Soc., vol. 66, no. 8, 1967, pp. 405-422.

8. Bhatt, R.T.: Properties of Silicon Carbide Fiber-Reinforced Silicon Nitride Matrix Composites. NASA TM-101356, 1988.

TABLE I.-PROPERTIES OF SIC/RBSN COMPOSITES BEFORE

AND AFTER OXIDATION

\begin{tabular}{|c|c|c|c|c|}
\hline Properties/Sample, GPa & 745 & $745 \mathrm{~A}$ & $745 \mathrm{~B}$ & $745 \mathrm{C}$ \\
\hline Density (dry), g/cc & 2.51 & 2.48 & 2.55 & 2.50 \\
\hline Density (wet), g/cc & 2.70 & 2.68 & 2.58 & 2.59 \\
\hline $\mathrm{C}_{11}$ & 207 & 161 & 203 & 203 \\
$\mathrm{C}_{22}$ & 118 & 87.7 & 67.5 & 78.6 \\
$\mathrm{C}_{33}$ & 120 & 79.4 & 55.4 & 66.6 \\
$\mathrm{C}_{12}$ & 32.3 & N/A & N/A & 20.1 \\
$\mathrm{C}_{13}$ & 32.0 & 28.9 & 15.9 & 20.1 \\
$\mathrm{C}_{23}$ & 33.4 & N/A & N/A & 17.9 \\
$\mathrm{C}_{44}$ & 40.1 & N/A & N/A & 26.3 \\
$\mathrm{C}_{55}$ & 45.2 & 24.0 & 24.4 & 30.6 \\
$\mathrm{C}_{86}$ & 43.4 & N/A & N/A & 31.2 \\
\hline
\end{tabular}




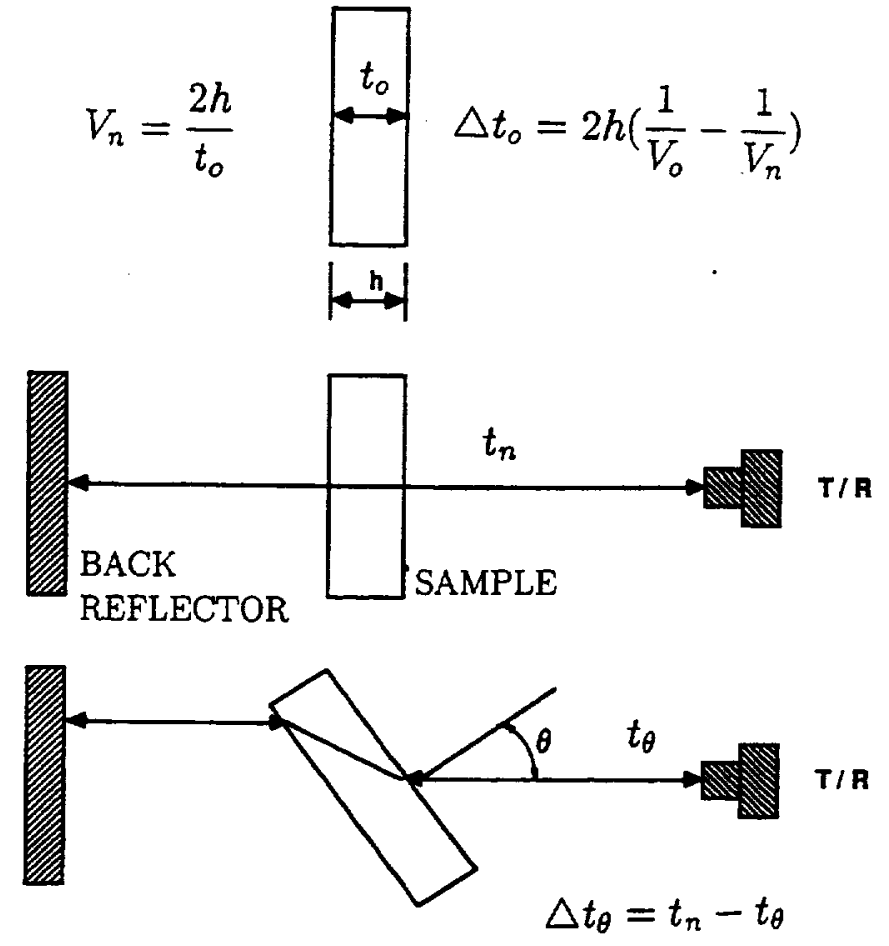

Figure 1.-Schematic diagram of the self-reference bulk wave method.

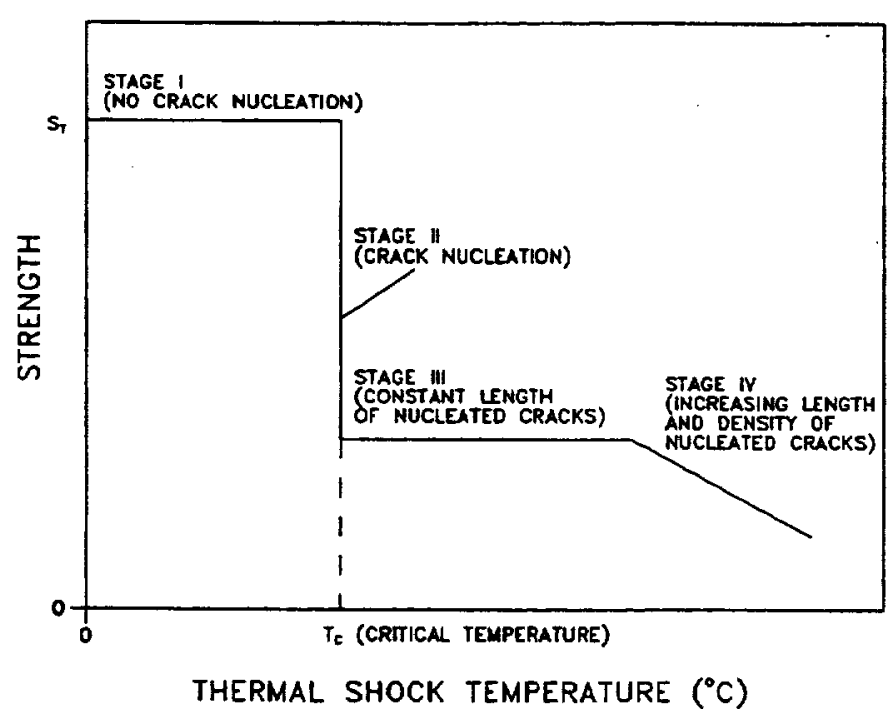

Figure 3.-Schematic representation of strength behavior as a function of severity of thermal shock as predicted by theory [2].

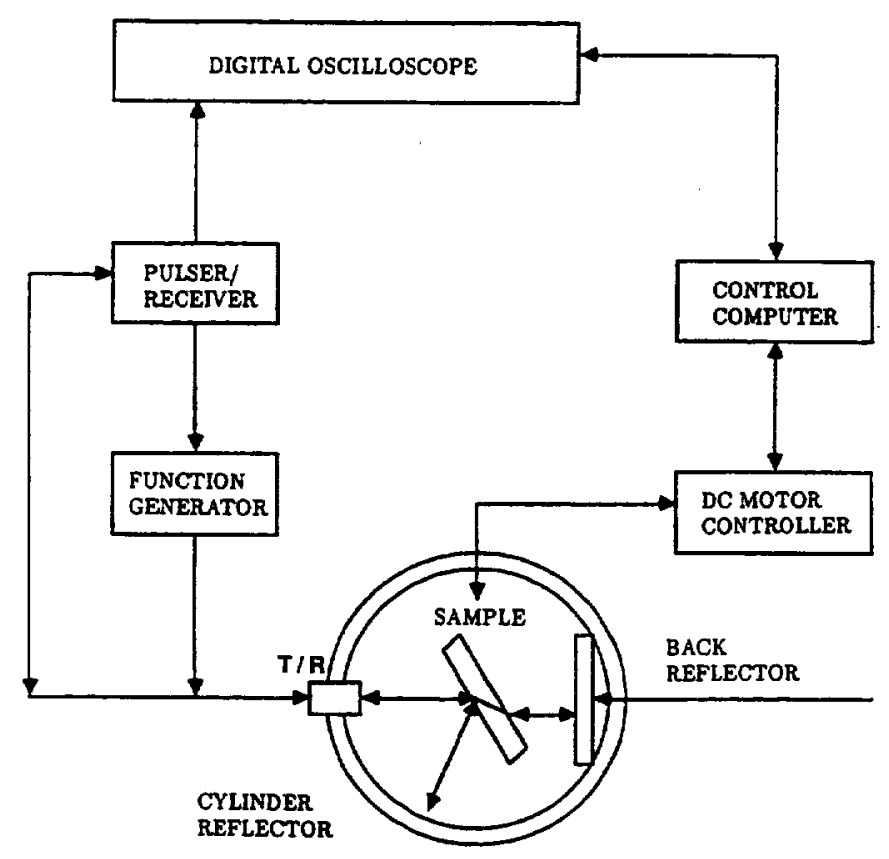

Figure 2.-Schematic diagram of the experimental apparatus for ultrasonic determination of elastic constants.

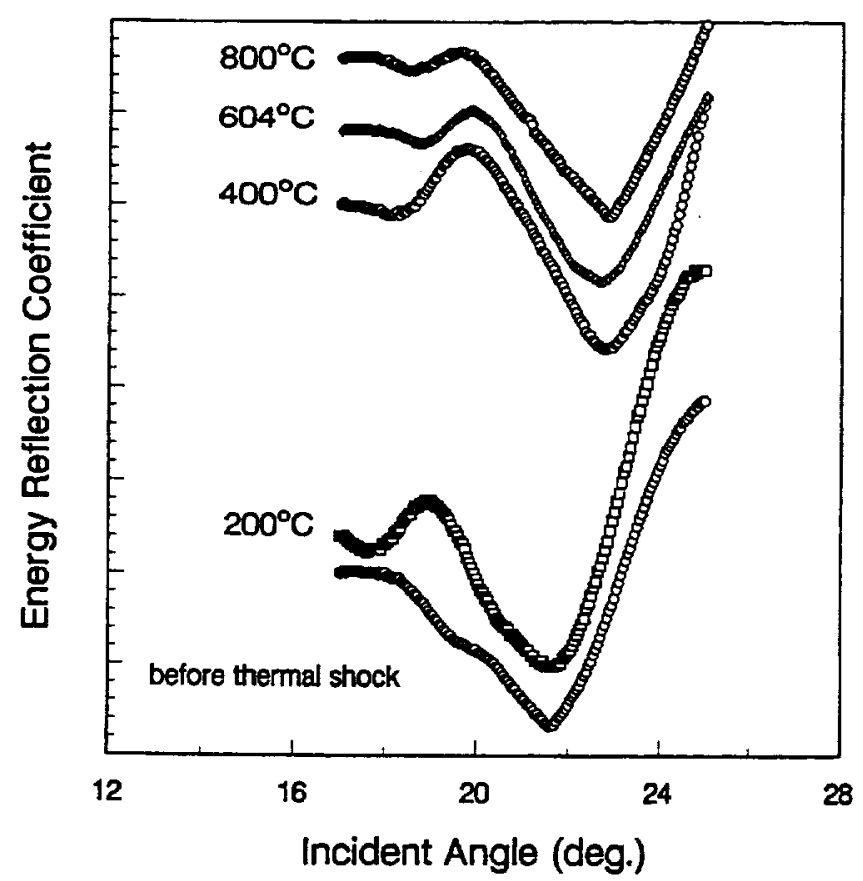

Figure 4.-Change of Rayleigh critical angle due to thermal shock for RBSN (2.25 MHz). 


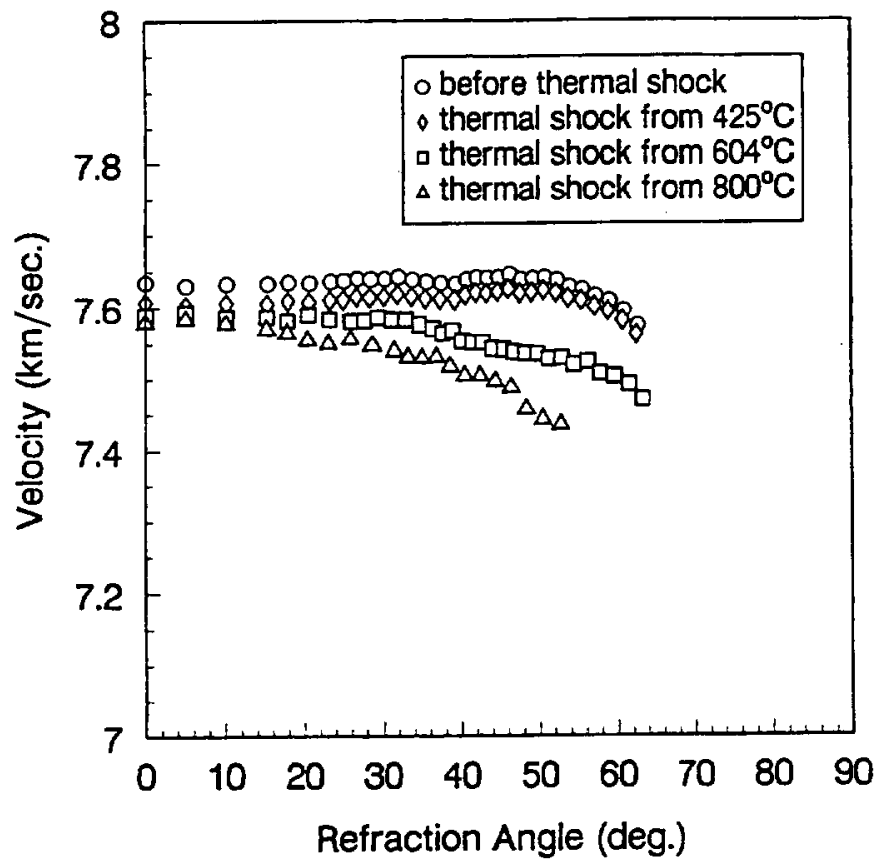

Figure 5.-Effect of thermal shock on velocities of longitudinal waves inside RBSN ceramics.

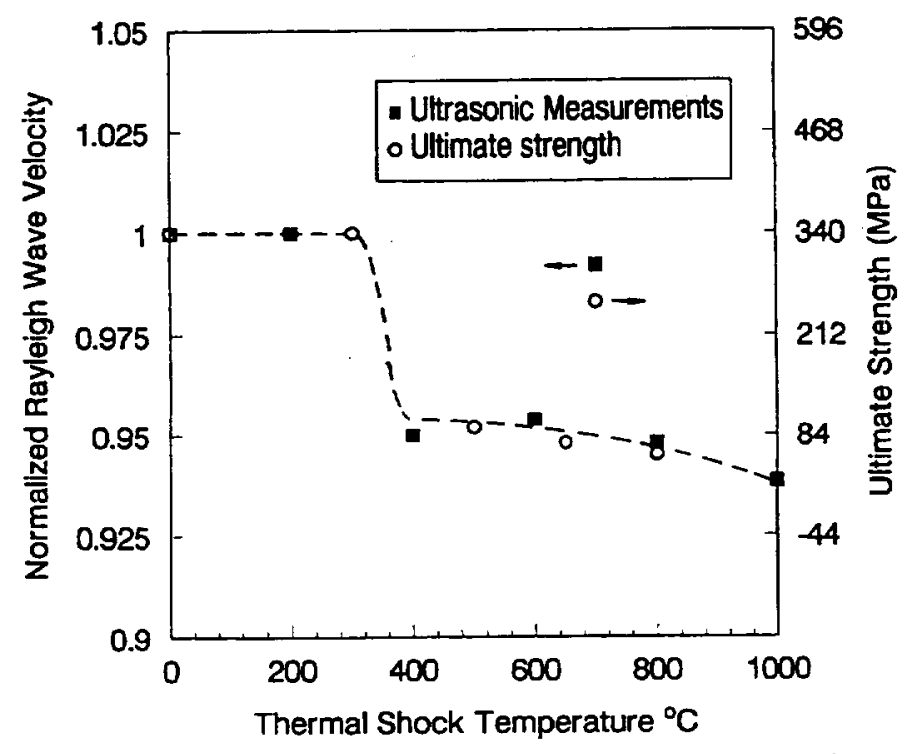

Figure 6.-Effect of thermal shock on Rayleigh wave velocities of RBSN ceramics.

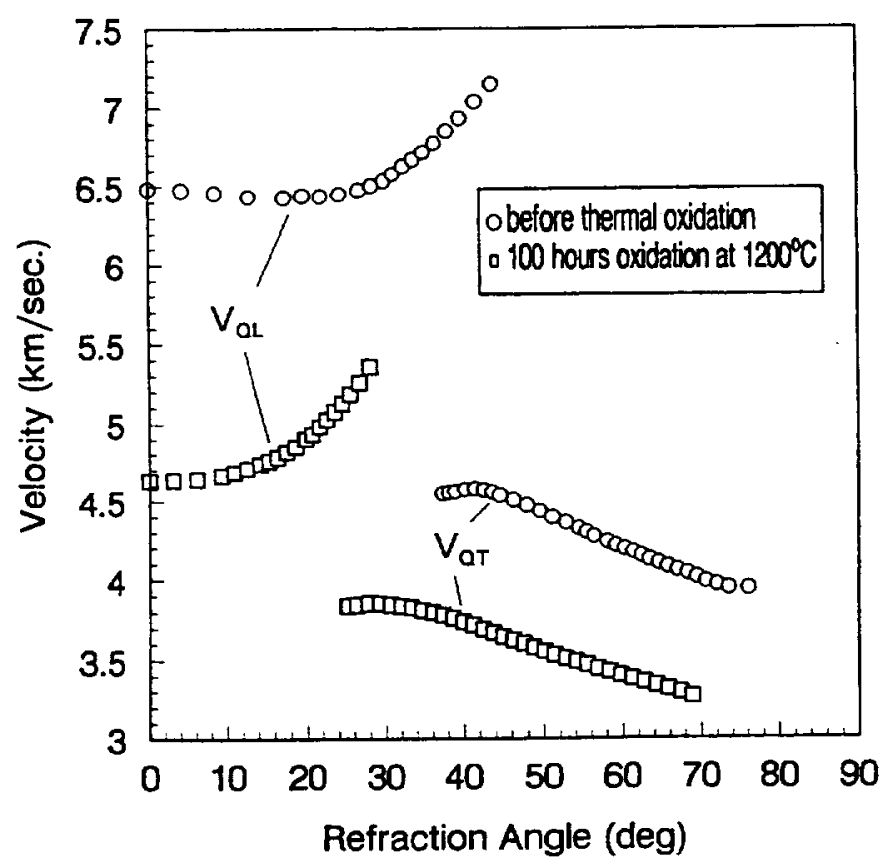

Figure 7.-Effect of thermal oxidation on wave velocities of $\mathrm{SiCl}$ RBSN composites. 


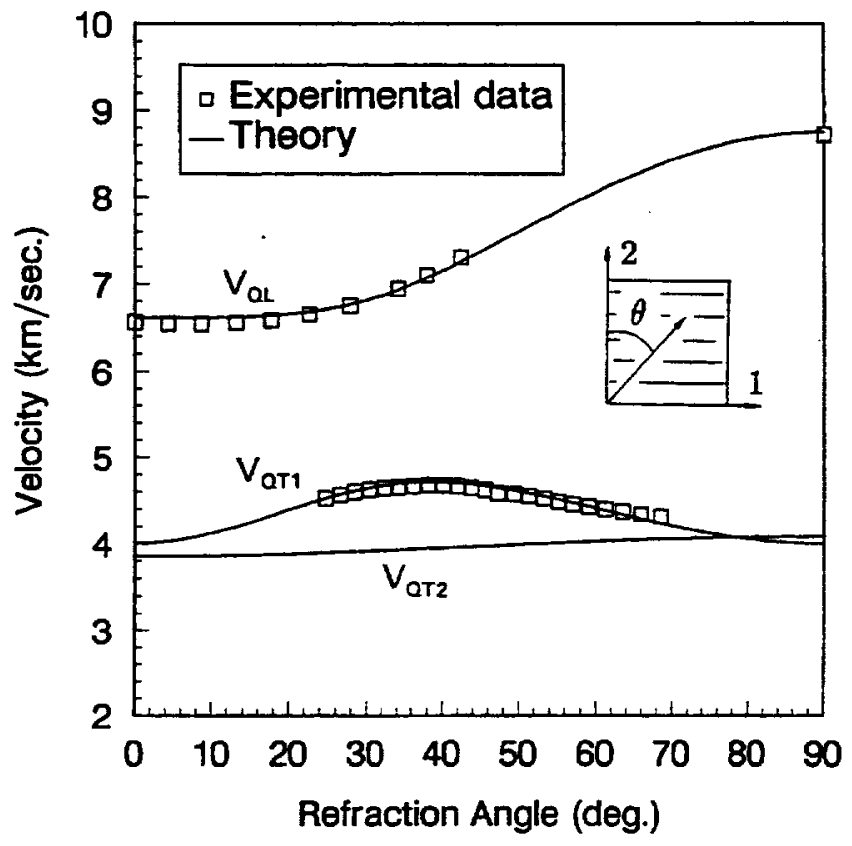

Figure 8.-The measured and calculated phase velocities for sample \$745 in the 1-2 plane as a function of refraction angle. The measured data are shown as discrete points and the solid lines are theoretical values calculated from the reconstructed elastic constants.

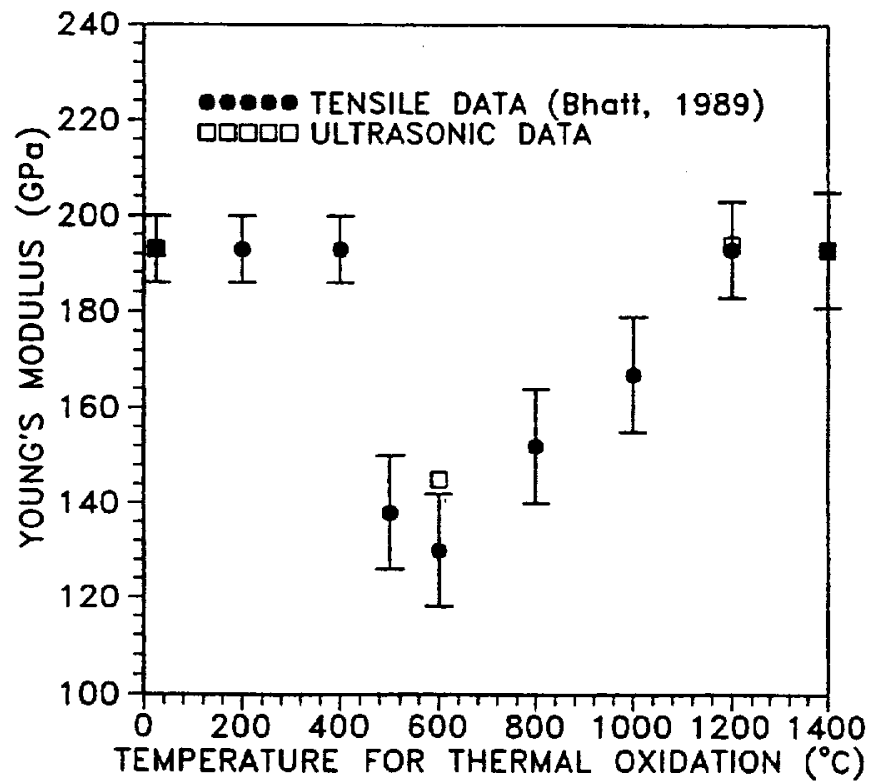

Figure 9.-The reduction of compostie longitudinal Young's modulus as a function of oxidation temperatures. 
Public reporting burden for this collection of information is estimated to average 1 hour per response, including the time for reviewing instructions. searching existing data sources, gathering and maintaining the data needed, and completing and reviewing the collection of information. Send comments regarding this burden estimate or any other aspect of this collection of information, including suggestions for reducing this burden, to Washington Headquarters Services. Directorate for Information Operations and Reports, 1215 Jefferson Davis Highway, Suite 1204, Arlington, VA 22202-4302, and to the Office of Management and Budget. Paperwork Reduction Project (0704-0188), Washington, DC 20503.

\begin{tabular}{|l|c|l|}
\hline 1. AGENCY USE ONLY (Leave blank) & $\begin{array}{c}\text { 2. REPORT DATE } \\
\text { May } 1993\end{array}$ & $\begin{array}{r}\text { 3. REPORT TYPE AND DATES COVERED } \\
\text { Technical Memorandum }\end{array}$ \\
\hline
\end{tabular}

4. TITLE AND SUBTITLE

5. FUNDING NUMBERS

Assessment of Damage in Ceramics and Ceramic Matrix Composites Using

Ultrasonic Techniques

6. AUTHOR(S)

WU-510-01-50

Y.C. Chu, G.Y. Baaklini, and S.I. Rokhlin

7. PERfORMING ORGANIZATION NAME(S) AND ADDRESS(ES)

National Aeronautics and Space Administration

Lewis Research Center

Cleveland, Ohio 44135-3191

8. PERforming óganization REPORT NUMBER

E-7785

9. SPONSORING/MONITORING AGENCY NAME(S) AND ADDRESS(ES)

10. SPONSORING/MONITORING AGENCY REPORT NUMBER

National Aeronautics and Space Administration

Washington, D.C. 20546-0001

NASA TM-106121

11. SUPPLEMENTARY NOTES

Y.C. Chu, The Ohio State University, Department of Welding Engineering, 190 West 19th Ave., Columbus, Ohio 43210; G.Y. Baaklini, NASA Lewis Research Center; and S.I. Rokhlin, The Ohio State University, Department of Welding Engineering, 190 West 19th Ave., Columbus, Ohio 43210. Responsible person, G.Y. Baaklini, (216) 433-6016.

\begin{tabular}{l|l} 
12a. DISTRIBUTION/AVALABILJTY STATEMENT & 12b. DISTRIBUTION CODE
\end{tabular}

Unclassified - Unlimited

Subject Categories 38 and 24

13. ABSTRACT (Maximum 200 words)

This paper addresses the application of ultrasonic sensing to damage assessment in ceramics and ceramic matrix composites. It focuses on damage caused by thermal shock or oxidation at elevated temperatures, which often results in elastic anisotropy. This damaged-induced anisotropy is determined by measuring the velocities of ultrasonic waves in different propagation directions. Thermal shock damage is assessed in ceramic samples of reaction bonded silicon nitride (RBSN). Thermal shock treatment from different temperatures up to $1000^{\circ} \mathrm{C}$ is applied to produce the microcracks. Results indicate that most microcracks produced by thermal shock are located near sample surfaces. Ultrasonic measurements using the surface wave method are found to correlate well with measurements of degradation of mechanical properties obtained independently by other authors using destructive methods. Oxidation damage is assessed in silicon carbide fiber/reaction bonded silicon nitride matrix (SCS-6/RBSN) composites. The oxidation is done by exposing the samples in a flowing oxygen environment at elevated temperatures, up to $1400^{\circ} \mathrm{C}$, for $100 \mathrm{hr}$. The Young's modulus in the fiber direction as obtained from ultrasonic measurements decreases significantly at $600^{\circ} \mathrm{C}$ but retains its original value at temperatures above $1200^{\circ} \mathrm{C}$. This agrees well with the results of destructive tests by other authors. On the other hand, the transverse moduli obtained from ultrasonic measurements decrease continually until $120{ }^{\circ} \mathrm{C}$. Measurements on the shear stiffnesses show behavior similar to the transverse moduli. The results of this work show that the damage-induced anisotropy in both ceramics and ceramic matrix composites can be determined successfully by ultrasonic methods. This suggests the possibility of assessing damage severity using ultrasonic techniques.

14. SUBJECT TERMS

SiC/RBSN; Ceramic matrix composites; Thermal shock; Thermal oxidation; Mechanical properties; NDE; Ceramics

\begin{tabular}{|c|c|}
\hline $\begin{array}{l}\text { 17. SECURTY CLASSIFICATION } \\
\text { OF REPORT }\end{array}$ & $\begin{array}{c}\text { 18. SECURITY CLASSIFICATION } \\
\text { OF THIS PAGE } \\
\text { Unclassified }\end{array}$ \\
Unclassified
\end{tabular}

19. SECUATY CLASSIFICATION OF ABSTRACT Unclassified 